\title{
THE DURATION OF LEFT VENTRICULAR SYSTOLE IN MITRAL INCOMPETENCE
}

\author{
BY \\ P. G. F. NIXON AND G. R. WAGNER \\ From the Department of Medicine and Thoracic Surgery, in the General Infirmary at Leeds \\ Received December 11, 1961
}

In mitral incompetence the left ventricle has two exits and it has been suggested that diminished resistance to emptying causes left ventricular systole to be shorter than normal (Brigden and Leatham, 1953). Theoretically the elevation of left ventricular end-diastolic pressure that is found in severe mitral incompetence (Ross et al., 1958; Nixon, 1961a) should result in prolongation of systole. The purpose of this communication is to report measurements of left ventricular systole in patients with mitral incompetence, and to consider their significance.

\section{Material AND Methods}

Patients with chronic rheumatic mitral valvular disease submitted to diagnostic left heart catheterization were selected for this study provided they were free from evidence of congestive heart failure, aortic valvular, hypertensive, or ischæmic heart disease: six had atrial fibrillation and were severely disabled by their mitral disease. During cardiac catheterization mean arterial blood pressure lay between 80 and $100 \mathrm{~mm}$. $\mathrm{Hg}$ in five cases; in one it was $110 \mathrm{~mm}$. $\mathrm{Hg}$. Pulmonary hypertension was present, average pulmonary arterial systolic pressures lying between 40 and $60 \mathrm{~mm}$. $\mathrm{Hg}$. The diagnosis of pure or predominant incompetence was made from the presence of all of the following findings: clinical and radiological evidence of left ventricular enlargement; left ventricular apical impulse displacement curves (Schneider and Klunhaar, 1961) showing a prominent "third heart sound wave", and evidence of ventricular stasis in diastole (Fig. 1); a loud mitral pansystolic murmur; a third heart sound and the mitral diastolic murmur characteristic of incompetence (Fig. 1 and 2) (Nixon and Wooler, 1960; Nixon, $1961 a$ and $b$ ); ready equalization of left atrial and ventricular pressures in diastole (Fig. 2) and a left atrial stasis wave (Nixon and Wooler, 1961); gross distortion of the indicator-dilution curves obtained by injecting blue dye into the left atrium (Nixon and Snow, 1962). The diagnosis was confirmed at operation in the four patients who were treated surgically; the long diameters of their mitral orifices measured $2 \cdot 5,3 \cdot 0,3 \cdot 5$, and $5 \cdot 0 \mathrm{~cm}$. respectively.

At investigation an indwelling needle was inserted into the brachial artery: transeptal catheterization of the left atrium was performed in the manner described previously (Nixon, 1960) and the left ventricle was entered by percutaneous puncture. During expiratory pauses pressures were recorded simultaneously using equisensitive Statham P23G gauges and a photographic recorder having a paper speed of $80 \mathrm{~mm}$./sec. The zero reference point was the sternal angle. Mitral and $\stackrel{\mathscr{\Phi}}{?}$ pulmonary area phonocardiograms and the lead II electrocardiogram were recorded simultaneously with the pressure pulses.

Ten complexes were studied in each of five patients and eight complexes in one patient. The duration of systole was measured from the start of the systolic rise in left ventricular pressure to the $\stackrel{\unrhd}{\perp}$ onset of the second heart sound vibrations on the phonocardiogram (Fig. 2). The measurement $\sigma_{2}$ therefore included the pre-isovolumetric rise in tension, the isovolumetric phase, the period of 8 


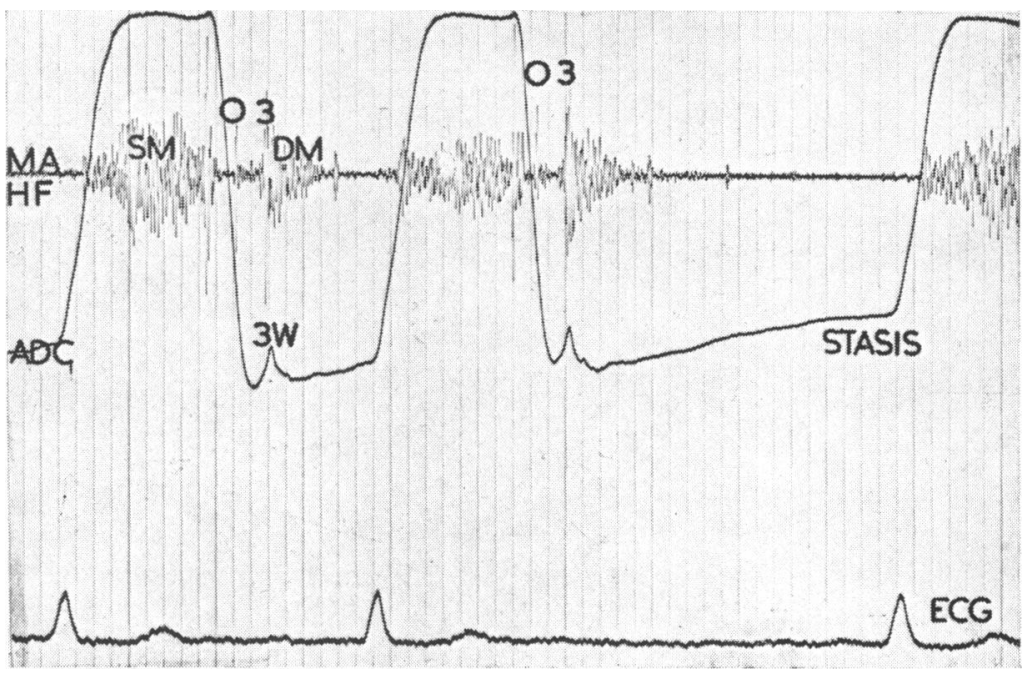

Fig. 1.-Severe mitral incompetence. Mitral area phonocardiogram (MA/HF), left ventricular apical impulse displacement curve (A.D.C.), and electrocardiogram (E.C.G.). The phonocardiogram shows a pansystolic murmur (S.M.), loud opening snap (O), third heart sound (3), and a diastolic murmur (D.M.) that begins loudly at the time of the third sound. The displacement curve shows transient reversal of outward movement of the apex from the peak of the large "third heart sound wave" (3.W.), and cessation of outward movement in diastasis (STASIS).

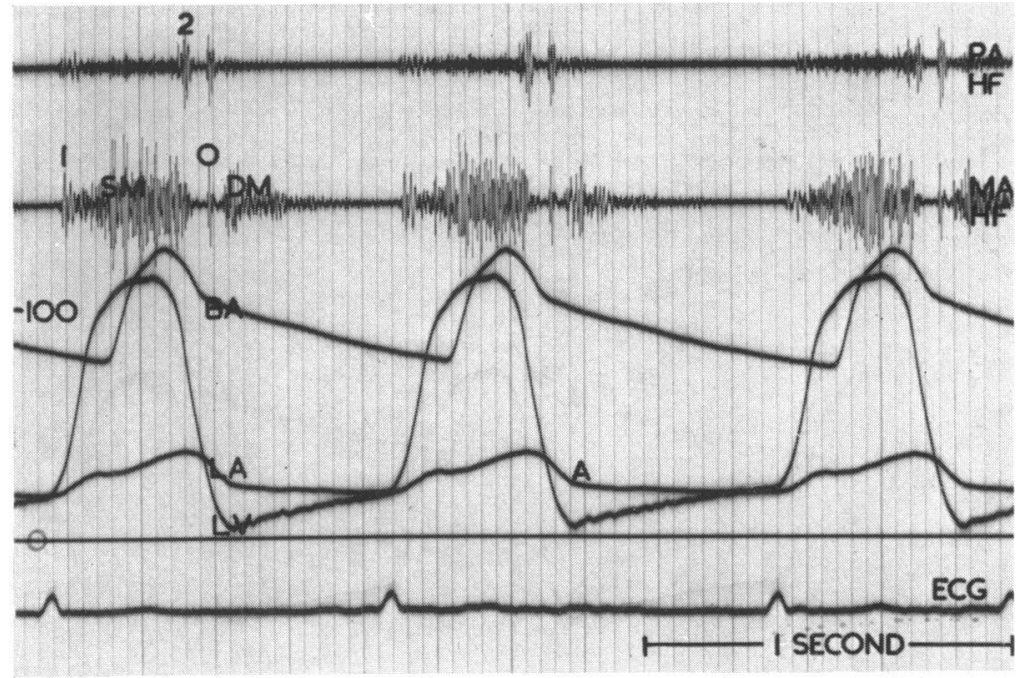

Fig. 2.-Severe mitral incompetence. Pulmonary area (P.A./H.F.) and mitral area (M.A./H.F.) phonocardiograms, brachial arterial (B.A.), left atrial (L.A.) and left ventricular (L.V.) pressure pulses, and electrocardiogram (E.C.G.) recorded at cardiac catheterization. Atrial and ventricular pressures equalize in diastole. 1,2=first and second heart sounds. $\mathrm{O}=$ mitral opening snap. S.M. =mitral pansystolic murmur. D.M.=diastolic murmur of mitral incompetence beginning at the left atrial annular ascent point (A), and fading away as atrial and ventricular pressure equalize. 
ejection, and protodiastole. Allowance was made for the 2.5 millisecond lag between pressure and sound recording channels that was determined by experiment. The term "isovolumetric" is preferred to the more widely used "isometric" for the reasons given by Rushmer (1961). Protodiastole was included in the measurements of systole because it is difficult to recognize on most tracings; this probably introduces an error of the order of $0.02 \mathrm{sec}$. (Braunwald et al., 1956). The duration of the ejection phase was measured from the beginning of the brachial arterial upstroke to the nadir of the incisura on the downstroke, and the measurement probably included protodiastole. The length of the preceding cycle, and the end-diastolic left ventricular pressure of the preceding cycle were measured.

A seventh patient presented with a mitral pansystolic murmur and sinus rhythm, and had no disability. Pulmonary arterial pressure was $15 / 0 \mathrm{~mm}$. Hg. Left ventricular puncture was not performed but left atrial and ventricular pressures were obtained by the transeptal route, and recorded with simultaneous phonocardiograms. These pressures and the indicator-dilution curves were consistent with a diagnosis of slight mitral incompetence. The durations of systole and of the ejection phase were measured as in the disabled cases.

\section{RESULTS}

The heart rate was generally slow during the investigation and the majority of cardiac cycles measured between 0.7 and 1.2 seconds.

The duration of systole in 58 cardiac cycles from the six disabled patients is plotted against the length of the preceding cardiac cycle in Fig. 3. The shortest systole measured $0.3 \mathrm{sec}$. the longest $0.39 \mathrm{sec}$. and the average was about $0.36 \mathrm{sec}$. When measurements from a number of

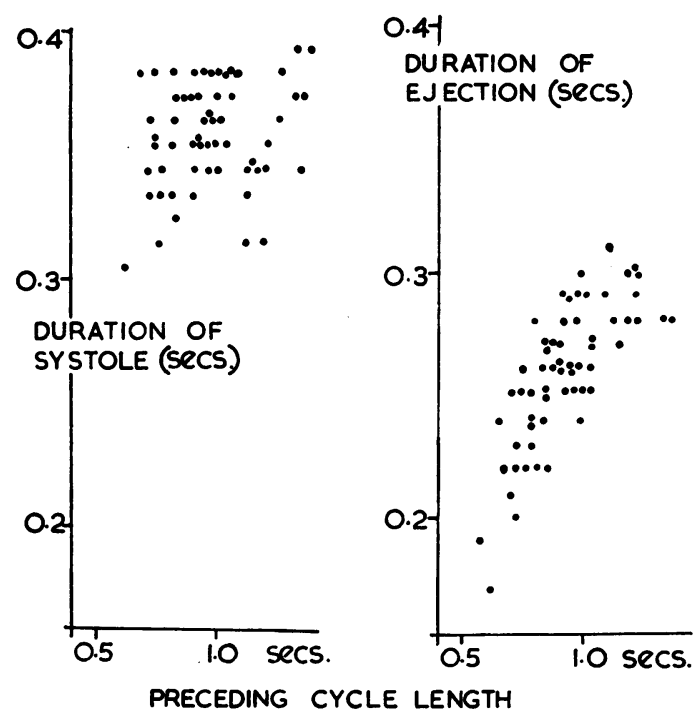

FIG. 3.-Severe mitral incompetence with atrial fibrillation. The duration of left ventricular systole and the duration of left ventricular ejection plotted against the length of the preceding heart cycle. Fifty-eight observations from six patients.

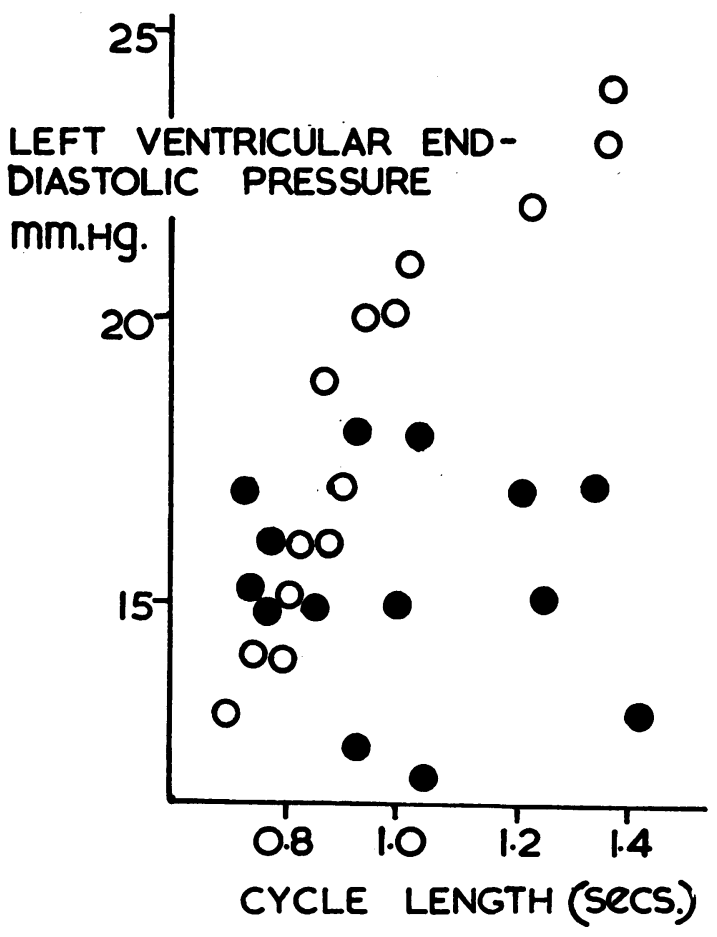

FIG. 4.-Severe mitral incompetence with atrial fibrillation. Left ventricular end-diastolic pressure plotted against cycle length. Measurements from one patient are indicated by open circles, and from a second patient by closed circles. 
patients are grouped in this way there appears to be no obvious relation between the duration of systole and the length of the preceding cycle.

The duration of the ejection phase in 58 cardiac cycles from the six disabled patients is plotted against the length of the preceding cycle in Fig. 3. When measurements from a number of patients are so grouped it may be seen that the period of ejection tends to lengthen directly with the duration of the preceding cycle. The shortest and longest ejection phases measured 0.17 and $0.31 \mathrm{sec}$. respectively, with an average of about 0.26 sec.

In the patient with sinus rhythm and little or no disability cycle lengths varied between 0.65 and $0.74 \mathrm{sec}$; systole measured between 0.29 and $0.31 \mathrm{sec}$. and the ejection phase was constantly $0.25 \mathrm{sec}$. in duration.

Average left ventricular end-diastolic pressures in the six disabled patients were 15, 17, 10, 14, 13 , and $21 \mathrm{~mm}$. $\mathrm{Hg}$ respectively. In the patient without disability left ventricular diastolic pressure measured just before atrial contraction was zero.

\section{Discussion}

The durations of the phases of systole in man were determined by Katz and Feil (1923) and Wiggers (1928). Their results are shown in Table I, together with the measurements from patients

TABLE I

\begin{tabular}{|c|c|c|c|c|c|c|}
\hline \multirow{2}{*}{\multicolumn{2}{|c|}{ Phase of the cardiac cycle }} & \multirow[b]{2}{*}{.. } & \multirow{2}{*}{$\begin{array}{c}\begin{array}{c}\text { Duration } \\
\text { (seconds) } \\
\text { Katz and Feil }\end{array} \\
\text { Normal }\end{array}$} & \multirow{2}{*}{$\begin{array}{c}\begin{array}{c}\text { Duration } \\
\text { (seconds) } \\
\text { Wiggers }\end{array} \\
\text { Normal }\end{array}$} & \multicolumn{2}{|c|}{ Duration (seconds) mitral incompetence } \\
\hline & & & & & No disability & Severe disability \\
\hline Total systole & . & .. & $0.262-0.374$ & $0 \cdot 27$ & $0 \cdot 295-0 \cdot 31$ & $\begin{array}{c}0.3-0.39 \\
\text { (Average approximately } 0.36 \text { ) }\end{array}$ \\
\hline Ejection & . & .. & $0 \cdot 22-0 \cdot 298$ & $0 \cdot 22$ & $0 \cdot 25$ & $\begin{array}{c}0.17-0.31 \\
\text { (Average approximately } 0.26 \text { ) }\end{array}$ \\
\hline
\end{tabular}

studied in this investigation. In severe mitral incompetence it may be seen that the durations of systole and of the ejection phase lie in the upper range of normal values or are abnormally prolonged.

Katz and Feil (1923) observed that a change in the duration of diastole caused a like change in the duration of the subsequent ejection, but produced an opposite change in the duration of the isometric period. In the patients studied here alterations in the duration of ejection with heart rate were more or less equal and opposite to alterations in the pre-isovolumetric and isovolumetric periods, and so the duration of systole varied little from beat to beat.

The factors that determine the rate of rise of intraventricular pressure and the duration of ejection, in relation to cycle length, have been studied extensively, and recent observations in man (Braunwald et al., 1960) have confirmed Starling's opinion (1918) of the importance of end-diastolic myocardial fibre length in determining the characteristics of systole. Changes in left ventricular end-diastolic fibre length are generally accompanied by proportional changes in end-diastolic ventricular pressure, but the two may vary independently. When they vary independently it is the fibre length rather than the pressure that determines the character of systole (Braunwald et al., 1960). End-diastolic fibre length could not be estimated in our patients with severe incompetence, but left ventricular end-diastolic pressure was measured and found to be high. The level of ventricular end-diastolic pressure was examined in relation to cycle length, and the results from two patients are shown in Fig. 4. In one, cycle length and left ventricular end-diastolic pressure had an 
almost linear relationship; in the other the relationship seemed haphazard. It follows that end $-\stackrel{\vec{C}}{\mathrm{C}}$ diastolic pressure cannot be used as an estimate of end-diastolic myocardial fibre length in every $\overrightarrow{\vec{\rho}}:$ case. Nevertheless it is highly probable that the left ventricular diastolic hypertension of severe mitral incompetence does indicate abnormal lengthening of the left ventricular fibres, and that such $\frac{}{0}$ lengthening is responsible for the prolongation of systole.

\section{SUMmary}

The duration of left ventricular systole and of left ventricular ejection was in the upper range of $\vec{\circ}$ normal values or abnormally prolonged in six cases of severe mitral incompetence with atrial $\overrightarrow{\vec{\omega}}$ fibrillation. Prolongation of systole is attributed to increased left ventricular end-diastolic myo- ${ }^{\omega}$ cardial fibre length, the evidence for the presence of this being elevation of left ventricular enddiastolic pressure.

The authors are deeply indebted to Mr. G. H. Wooler and Professor R. E. Tunbridge for making this study possible. They are grateful to Mr. R. Addyman and Mrs. J. Blake for assistance, and to the Board of Governors of the United $\underset{\perp}{ }$ Leeds Hospitals, the Medical Research Council, and private benefactors for providing equipment.

\section{REFERENCES}

Braunwald, E., Fishman, A. P., and Cournand, A. (1956). Circulation Res., 4, 100.

, Frye, R. L., Aygen, M. M., and Gilbert, J. W. (1960). J. clin. Invest., 39, 1874.

Brigden, W., and Leatham, A. (1953). Brit. Heart J., 15, 55.

Katz, L. N., and Feil, H. S. (1923). Arch. intern. Med., 32, 672.

Nixon, P. G. F. (1960). Thorax, 15, 225.

- (1961a). Brit. Heart J. 23, 677.

- (1961b). Brit. Heart J., 23, 462.

- and Snow, H. M. (1962). Brit. Heart J. In press.

-, and Wooler, G. H. (1960). Brit. med. J., $2,1122$.

$\longrightarrow$, (1961). Brit. Heart J., 23, 161.

Ross, J. Jr., Braunwald, E., and Morrow, A. G. (1958). Amer. J. Cardiol., 1, 11.

Rushmer, R. F. (1961). Cardiovascular Dynamics. W. B. Saunders, London.

Schneider, H., and Klunhaar, E. W. J. M. (1961). Amer. Heart J., 61, 675.

Starling, E. H. (1918). The Linacre Lecture on the Law of the Heart. Longmans Green, London.

Wiggers, C. J. (1928). The Pressure Pulses in the Cardiovascular System. Longmans Green, London. 